\title{
O "TORÉ" E O ENSINO DE GEOGRAFIA as músicas indígenas na etnoeducação Potiguara da Paraíba
}

\author{
Sidnei Felipe da Silva ${ }^{1}$ \\ Leandro da Silva Ramos ${ }^{2}$
}

Resumo: A música é de suma importância para os povos indígenas Potiguara da Paraíba. Ela está presente no cotidiano desses povos, seja nos rituais, na pesca, na caça, na religião, nas plantações, nas atividades domésticas e em outros momentos que constituem o processo de produção do espaço da etnia. O Toré e suas melodias apresenta temáticas significativas para a geografia escolar, tais como: a questão territorial, a dinâmica natural (vegetação, clima, relevo, hidrografia), e a riqueza cultural e religiosa desses povos. A abordagem do Toré, como recurso didático-pedagógico no ensino de geografia nas escolas de educação diferenciada da etnia Potiguara tem como objetivo geral facilitar o ensinoaprendizagem de temáticas geográficas e (re)afirmar a identidade étnica e cultural. A metodologia proposta para esta ação pauta-se pela pesquisa bibliográfica sobre a Etnoeducação e a Geografia escolar por meio da análise documental dos Referenciais Curriculares para a Educação Indígena (RCNEI, 2005); apresenta abordagem qualitativa, por focar no caráter subjetivo do objeto, compreendendo suas particularidades.

Palavras-chave: Toré. Ensino de Geografia. Músicas Indígenas.

\section{THE "TORÉ" AND THE GEOGRAPHY TEACHING the indigenous songs in the Paraíba's Potiguara etnoeducation}

\begin{abstract}
Music is of the utmost importance to the indigenous peoples Potiguara da Paraíba. It is present in the daily life of these peoples, be it in rituals, fishing, hunting, religion, plantations, domestic activities and other moments that constitute the process of production of ethnic space. Toré and its melodies present significant themes for school geography, such as the territorial question, the natural dynamics (vegetation, climate, relief, hydrography), and the cultural and religious richness of these peoples. The Toré approach, as a didactic-pedagogical resource in the teaching of geography in schools of differentiated education of the Potiguara ethnic group, has as general objective to facilitate the teachinglearning of geographic topics and (re) affirm the ethnic and cultural identity. The methodology proposed for this action is guided by the bibliographic research on ethnoeducation and school geography through documentary analysis of the Curriculum Frameworks for Indigenous Education (RCNEI, 2005); presents a qualitative approach, because it focuses on the subjective character of the object, understanding its particularities.
\end{abstract}

Keywords: Toré. Geography Teaching. Indigenous Music.

\footnotetext{
${ }^{1}$ Doutorando em Geografia pela Universidade de Brasília (UnB) na área de concentração em Gestão Territorial e Ambiental. Integra o grupo de pesquisa - Ensino, Aprendizagem e Formação de Professores em Geografia da Universidade de Brasília - GEAF/UnB. E-mail: prof.sidnei.eageo@gmail.com

${ }^{2}$ Graduado em Geografia pela Universidade Estadual da Paraíba (UEPB). Graduando em Letras pela Universidade Federal da Paraíba (UFPB). E-mail: leandropotiguara@gmail.com
} 


\section{REVISTA ELETRÔNICA \\ DA GRADUAÇÃO/PÓS-GRADUAÇÃ̃O EM EDUCAÇÃO \\ UFG/REJ}

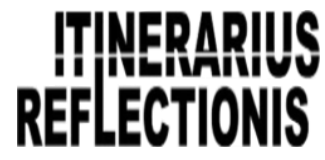

ISSN. 1807-9342

Volume 14, N. 2, 2018

\section{INTRODUÇÃO}

A educação escolar indígena tem um papel importante na (re)afirmação da cultura e tradição da etnia. É um ambiente onde os conhecimentos da comunidade indígena podem ser transmitidos, em que o papel do professor é ocupar este espaço tendo em vista uma escola em que o ensino de geografia se adeque e que considere a realidade desses povos.

Tendo como referência esse elemento, trazemos para essa discussão o Toré e as músicas indígenas como metodologia de ensino para a geografia escolar. Partindo da musicalidade da etnia Potiguara, as músicas indígenas se apresentam como possibilidade de instrumento para o ensino-aprendizagem de geografia, tendo como base o processo de valorização cultural e a busca pela fundamentação de uma identidade étnica. E, demonstra a importância da música, enquanto recurso didático para o ensino de geografia, evidenciando as relações entre o espaço geográfico e o ensino de geografia a partir das músicas e a preservação e (re)afirmação da identidade étnica cultural do povo Potiguara.

A geografia fornece à sociedade uma visão mais ampla e profunda em relação ao homem-natureza quanto ao espaço e suas transformações, onde a mesma mostra sua contribuição e compromisso como disciplina na educação básica e na construção de uma sociedade igualitária, na qual tem como objetivo auxiliar na formação de cidadãos conscientes, ativos e dotados de opinião própria.

Portanto, é através da música indígena, como recurso e instrumento pedagógico, que pretendemos estimular e motivar os alunos das escolas indígenas da Paraíba a aprender, a debater e a estudar sobre sua realidade, assim, tornando os conteúdos geográficos mais significativos e dinâmicos, e além de tudo, apontar a melodia como um referencial importante na cultura indígena da etnia Potiguara.

\section{OS POVOS INDÍGENAS POTIGUARA DA PARAÍBA: ocupação espacial e organização política}

O nosso texto busca fundamentação através da categoria de análise do território, uma vez que trata da questão das relações de poder que se estabelecem no espaço geográfico. Desde a antiguidade os grupos humanos apresentam a necessidade de se estabelecer em determinadas parcelas do espaço geográfico, que vão desde as mais remotas sociedades tribais até os modernos Estados nacionais e, por sua vez, os países, que possuem as mais variadas formas de 


\section{REVISTA ELETRÔNICA \\ DA GRADUAÇÃO/PÓS-GRADUAÇÃ̃ EM EDUCAÇÃO \\ UFG/REJ}

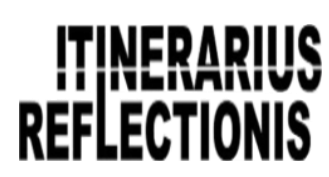

ISSN. 1807-9342

Volume 14, N. 2, 2018

gestão e controle do espaço geográfico. Entretanto, não devemos nos limitar apenas ao território nacional, pois dentro dele existem muitos outros, nas mais variadas condições, e sendo controlados por diferentes grupos sociais.

É relevante esclarecer que diante das categorias de análise do pensamento geográfico se imbricam o lugar, a paisagem e o território, que se interpenetram e se sobrepõem uns aos outros. Assim, ao analisar o território, uma série de outros conceitos precisam ser abordados e sem os quais a análise tornar-se-ia inviável. São eles: poder, limites e fronteira, ocupação e formação territorial, usos do espaço, conflito, dentre outros. Diante desta gama de conceitos que servem para viabilizar o estudo de território em nossa investigação, podemos sintetizá-los ao que nos parece a luz da análise da "territorialidade étnica", pois nossa pesquisa versa sobre resistência dos povos indígenas em nosso país e, particularmente, o povo Potiguara como exemplo de luta e resistência, que desde 1500 enfrentam os invasores de suas terras e permanecem nestes territórios até os dias atuais. A cerca dos conceitos de território na perspectiva da temática a ser analisada podemos sugerir as ideias do geógrafo Claude Raffestin:

[...] tomemos um exemplo referente ao Brasil: quando os portugueses chegaram em 1500, encontraram um território sistematizado pelos habitantes. Porém, (o território) não era delimitado, demarcado e, por isso, foi considerado pelos portugueses como um "espaço dado" que, naturalmente, poderia ser transformado. A diferença entre "dado" ou "ofertado" à ação e "criado" ou produzido pela ação deve ser evidenciada na geografia política e na geografia em geral. Os conceitos precisam ser derivados uns dos outros, por meio de uma teoria possível, com uma utilidade, pois vivemos numa ecogênese. Esta última observação é importante porque a geografia é dramaticamente ligada à linguagem cotidiana, que não tem nenhuma perspectiva teórica. Na linguagem cotidiana, o espaço é sinônimo de território e vice-versa: o único embrião teórico é fornecido pela pragmática da língua que oferece paradigmas, de modo que a palavra espaço ou território é utilizada conforme suas circunstâncias de uso (RAFFESTIN, 2010, p. 14).

O território é resultado do processo de territorialização e das territorialidades vividas por cada grupo social em cada relação espaço-tempo. São ideias que argumentam em favor de uma Geografia da territorialidade, e este viés da ciência geográfica pode ser compreendido através das reflexões sobre a territorialidade:

Sucintamente, a territorialidade (humana) significa relações de poder, econômicas, políticas e culturais; diferenças, identidades e representações; apropriações, domínios, demarcações e controles; interações e redes; 


\section{REVISTA ELETRÔNICA \\ DA GRADUAÇÃO/PÓS-GRADUAÇÃO EM EDUCAÇÃO \\ UFG/REJ}

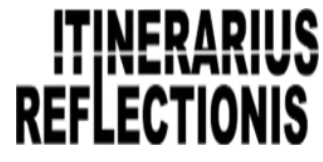

ISSN. 1807-9342

Volume 14, N. 2, 2018

degradação e preservação ambiental; práticas espaço-temporais e organização política, que envolvem, evidentemente, as apropriações, as técnicas e tecnologias, a degradação, o manejo, os pertencimentos etc (SAQUET, 2011, p. 16-17).

É importante compreender os conceitos de território e territorialidade para a realidade indígena, e dentro da abordagem de geografia que adotamos, são requeridos para a compreensão e o entendimento da escola comunidade indígena. É necessário estabelecermos um diálogo, com as possibilidades e confrontos entre o saber científico e o saber popular que age localmente ligado a uma matriz curricular diferenciada, construída em vários anos de discussão e luta.

Segundo Vieira (2004) a história dos povos Potiguara e o contato com os brancos remontam as primeiras tentativas europeias (portugueses, franceses e holandeses) de colonização e de comércio com a América do Sul. Durante todo o século XVI a coroa portuguesa tentou conquistar a Paraíba, e fracassaram diante da determinação dos Potiguara em defender suas terras. A aliança entre os Potiguara e os franceses foi decisiva na década de 1580, quando navios franceses aportaram na Baía da Traição e se uniram aos indígenas Potiguara para enfrentarem os portugueses, estes se aliaram a indígenas da etnia Tabajara, inimigos dos Potiguara. Apesar da destruição de três aldeias Potiguara na Serra da Copaoba, os Potiguara resistiram e foram vitoriosos neste conflito.

No final da década de 1580 do século XVI, os Potiguara cercaram a cidade de Nossa Senhora das Neves (atual João Pessoa), ao mesmo tempo os portugueses e seus aliados atacaram e destruíram as aldeias situadas na Baía da Traição, causando assim a rendição e fuga dos Potiguara. Em 1599, os Potiguara fazem as pazes com os Portugueses, após terem perdido o apoio dos franceses. Entretanto, a paz durou até a chegada dos holandeses, porém com a expulsão dos holandeses em 1654, ocorreu definitivamente a "pacificação" dos Potiguara (VIEIRA, 2004). Após a pacificação e o aldeamento dos Potiguara da Paraíba, no início do século XVII conforme Vieira (2004) os registros escritos e as informações sobre os Potiguara são mais escassas, permanecendo adormecidas até o século XX.

No século XX, Palitot (2005) afirma que nesse período poderosas organizações entraram na história dos Potiguara, tornando mais difícil a preservação destes. Estas agências são o Serviço de Proteção ao Índio (SPI) criado em 1910, que visava diminuir o crescimento dos grileiros no território Potiguara; e a Companhia de Tecidos de Rio Tinto (CTRT) cujos os registros indicam que a partir de 1917, teve início as obras de instalação de um complexo 


\section{REVISTA ELETRÔNICA \\ DA GRADUAÇÃO/PÓS-GRADUAÇÃO EM EDUCAÇÃO \\ UFG/REJ}

industrial têxtil, o qual acentuou e acelerou a invasão das terras indígenas, a destruição das matas em busca de madeira para construção da fábrica de tecidos na região do vale de Mamanguape - PB, assim como a matéria prima para a confecção do produto comercializado. Conforme a figura abaixo das chaminés do complexo industrial da CTRT funcionado a todo o vapor.

Com a falência da CTRT, durante a década de 1990, as terras que a mesma empresa dominava foram negociadas, ou seja, repassadas para as mãos de grupos de importantes usineiros de cana-de-açúcar. Este grupo de industriais surgia com muita força neste período, por consequência da crise energética global causada pela alta de preços do petróleo, pois em nosso país havia sido lançado o Programa Nacional do Álcool (PROÁLCOOL), instituído pelo Governo Federal em 1975, tinha como finalidade a obtenção de fontes alternativas de energia. Contando com o apoio do Governo Federal os grupos agroindustriais instalados na região a exemplo da Rio Vermelho Agropastoril, da Destilaria Miriri S/A e da Japungú Agroindustrial passaram a substituir os Lundgrens no controle da posse das terras da antiga CTRT, o que incluía os territórios dos povos indígenas Potiguara, tornando-se também verdadeiros inimigos destes, por desmatar terras agricultáveis, expulsar remanescentes arrendatários, foreiros e agricultores que resistiram às pressões causadas pela CTRT, mudando toda a paisagem dessas terras, transformando-as em um imenso "mar de cana" (SILVA, 2015).

Ser indígena no nosso país nos dias atuais, requer duas lutas fundamentais: pela identidade e pelo território. Este confronto relacionado ao território se realiza na intencionalidade de (re)conquistar, ampliar e/ou manter o que possui. A identidade e o território são as características da luta indígena que se apresentam desde o contato com os invasores europeus.

Neste início de século XXI, podemos constatar o ressurgimento dos povos indígenas Potiguara principalmente após a demarcação de suas terras. Segundo Marques (2009) do ponto de vista territorial e jurídico-político, as terras indígenas Potiguara estão subdivididas em três terras indígenas que são: Terra Indígena Potiguara, Terras Indígena Jacaré de São Domingos e a Terra Indígena Potiguara de Monte-Mór. De acordo com Silva (2015) a etnia Potiguara possui a maior população indígena do Nordeste etnográfico, uma das maiores populações do Brasil. Atualmente possuem aproximadamente 20 mil habitantes, que vivem nas terras indígenas distribuídas em 33 aldeias, em três municípios do litoral norte paraibano: Baía da 


\section{REVISTA ELETRÔNICA \\ DA GRADUAÇÃO/PÓS-GRADUAÇÃO EM EDUCAÇÃO \\ UFG/REJ}

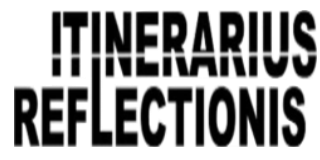

ISSN. 1807-9342

Volume 14, N. 2, 2018

Traição, Marcação e Rio Tinto. Como podemos observar no mapa de localização e distribuição territorial das terras indígenas Potiguara da Paraíba (fig. 1):

Figura 1: Mapa de localização das Terras Indígenas Potiguara da Paraíba.

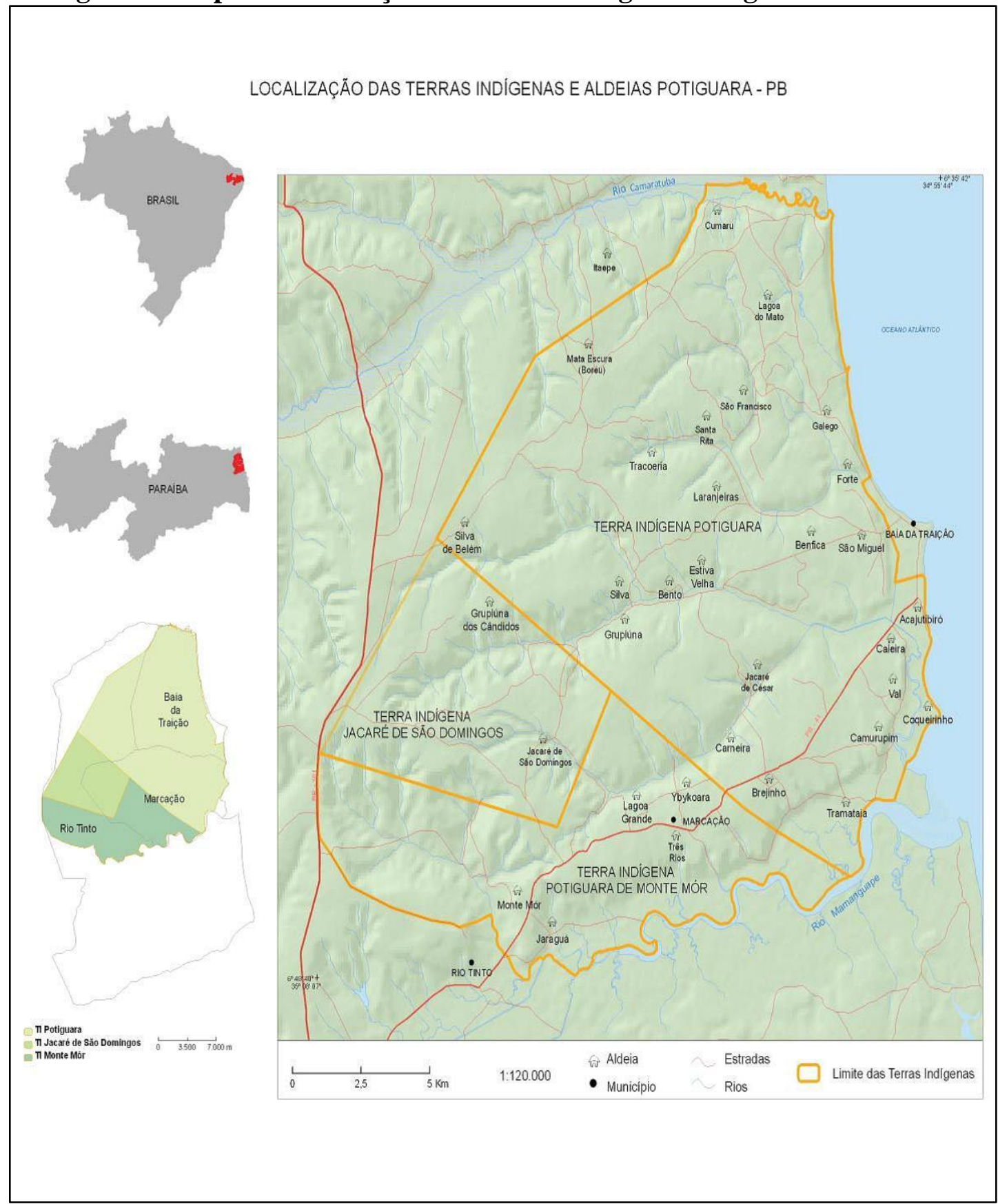

Fonte: Cardoso e Guimarães, 2012

As representações desse processo histórico, são reforçadas pelas lutas e conquistas deste povo, como podemos perceber neste mapa a demarcação territorial, foi marcada por um 


\section{REVISTA ELETRÔNICA \\ DA GRADUAÇÃO/PÓS-GRADUAÇÃO EM EDUCAÇÃO \\ UFG/REJ}

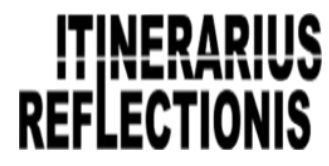

ISSN. 1807-9342

Volume 14, N. 2, 2018

processo de luta para se conseguir esse reconhecimento e demarcação, e ainda mais, pela presença de elementos de ordem sociológica que permitiram a manutenção e a positividade de uma identidade étnica indígena que serviu de abrigo à existência dos Potiguara, enquanto grupo dentro da sociedade, que são “Os Ritos”(BARCELLOS, 2012).

A organização política Potiguara é composta por um Cacique Geral, e um Conselho de Lideranças, formado pelos líderes das aldeias que são os caciques; cada aldeia também tem um Pajé (chefe religioso), vários anciãos e nove pessoas mais antigas da aldeia.

Estes preservam as raízes históricas na defesa da terra coletiva, sendo que os caciques são escolhidos pela maioria da comunidade indígena através de votação, para representar os interesses da coletividade na interação da coletividade com a sociedade envolvente e zelar pela harmonia nas aldeias.

Outras características fazem parte da cultura deste povo, tais como: os conhecimentos de plantas medicinais, a reza, as comidas, as lendas, os artesanatos e a mitologia difundida pela cultura oral e suas pinturas corporais que tem vários significados: Pintura da caça (jabuti e do favo da abelha), pintura de guerra, pintura de vitória. Essas tintas são extraídas do urucum e o jenipapo e suas vestes são saias de embira de jangadas, colares feitos de sementes.

Porém, a principal característica cultural dos povos indígenas do Nordeste centra-se nas musicalidades, que se apresentam para cada etnia, seja em seus rituais, ou no seu dia a dia, como podemos observar mais adiante o quanto as melodias e sua criação, são de suma importância para os povos Potiguara. Vale ressaltar que os ritos, as festas e as características desse povo são expressos nas músicas, daí a importância da discussão dessa dimensão cultural. O movimento de localização da cultura pode acarretar em uma retomada das tradições locais, num processo de busca por traços culturais, que assinalam a diferença entre os povos e o pertencimento destes aos seus territórios de origem. Os povos indígenas Potiguara atualmente estão vivenciando este processo de reafirmação étnica e cultural (LEITE, 2012).

\section{TORÉ, ENSINO DE GEOGRAFIA E A MÚSICA POTIGUARA No CONTEXTO ESCOLAR INDÍGENA}

Em relação aos mitos do povo Potiguara é relevante salientar como a academia está realizando suas pesquisas em relação à cultura indígena desta etnia como afirma Nascimento, 


\section{REVISTA ELETRÔNICA \\ DA GRADUAÇÃO/PÓS-GRADUAÇÃ̃O EM EDUCAÇÃO \\ UFG/REJ}

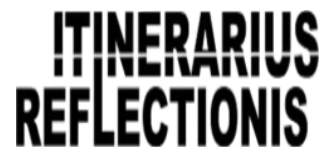

ISSN. 1807-9342

Volume 14, N. 2, 2018

[...] Na Universidade Federal da Paraíba (UFPB), o Programa de PósGraduação em Ciências da Religião (PPCGR) apresenta diversas linhas de pesquisa, entre elas a linha da Religiosidade Popular. Esta linha tem interesse pelo fenômeno da Crença Religiosa, no sentido mais amplo de sua manifestação, quer em produções antigas ou modernas, quer em tradições orais ou escritas. Abarca estudos de antigas civilizações (Roma, Grécia, Índia) como também modernas representações populares. De modo especial, centra sua atenção na religiosidade popular do Nordeste brasileiro, com seus messianismos e milenarismos, e nas manifestações indígenas e afrobrasileiras. Diante deste contexto, tem um olhar focado no respeito e valorização pela população indígena com a intenção de minimizar toda a imagem distorcida que os brasileiros têm dessa etnia (NASCIMENTO, 2012, p. 45).

Conforme Eliade (2007), os ritos reavivam os mitos, porque neles são encontradas formas de manter eles sempre vivos na mente do povo de uma determinada etnia. No caso dos Potiguara, fica evidenciada tal afirmação em seus rituais como o Toré, a dança do fogo, a dança da mandioca, as missas e os cultos. E dentre os rituais acima citados o mais valorizado pelo povo Potiguara devido a sua importância em relação ao ressurgimento desta etnia, e para os autores Barcellos e Soler (2012, p. 187):

Falar do Toré Potiguara é falar da vida indígena na sua mais profunda dimensão. O Toré é um dos principais rituais sagrados dos povos indígenas no Nordeste. Trata-se de uma expressão lúdica e organizadora, íntima e emblemática, definida pelos indígenas como tradição, união e crença, que é atualmente uma prática conhecida e presente na maioria das coletividades que se reivindicam como indígenas. Entre os Potiguara, o Toré é uma das principais práticas religiosas como também um dos mais importantes sinais de diacriticidade e de referência paradigmática de etnicidade.

O Toré, na visão dos Potiguara, segundo a cartilha "Os Potiguara pelos Potiguara" (2005) que foi elaborada por professores e alunos Potiguara de Baía da Traição, é um ritual indígena que é dançado em forma de círculo, com o acompanhamento musical de gaitas, tambores e maracás. É um ritual sagrado para os Potiguara, e é dançado em momentos especiais para eles, sendo esta expressão um símbolo da luta e resistência dos índios durante todos esses anos. Eles têm no som dos tambores e da gaita uma representação de que os nossos guerreiros ainda lutam e resistem em suas terras aos invasores. Para eles o Toré significa a sua própria cultura, durante a dança são entoadas músicas que retratam os momentos de lutas e vitórias, relatando também as crenças e a beleza das matas e dos animais nativos, sendo essas canções escolhidas de acordo com a cerimônia. Eles afirmam também que para dançar o toré devem 


\section{REVISTA ELETRÔNICA \\ DA GRADUAÇÃO/PÓS-GRADUAÇÃO EM EDUCAÇÃO \\ UFG/REJ}

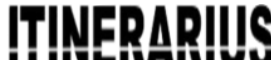 \\ REFLECTIONIS}

ISSN. 1807-9342

Volume 14, N. 2, 2018

fazer pinturas em seus corpos com o urucum e jenipapo para tornar ainda mais belo e original o ritual, como podemos visualizar nas figuras abaixo a importância deste belíssimo ritual para a etnia Potiguara em todas as aldeias do litoral norte paraibano.

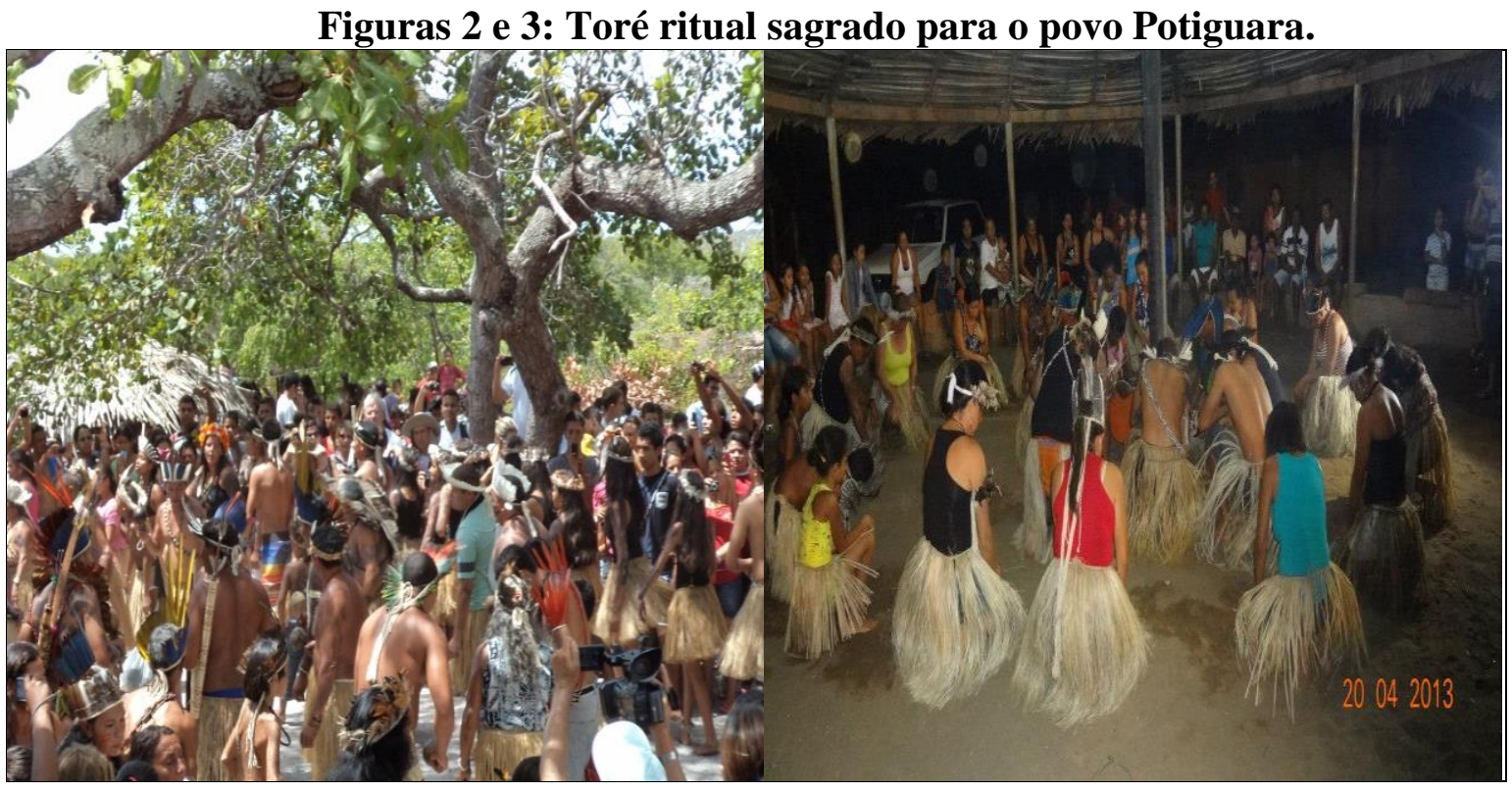

Fonte: Silva, 2015.

Ainda devemos nos reportar a outras riquezas que a cultura indígena Potiguara possui como as suas músicas que são cantadas nos rituais e retratam a diversidade cultural e religiosa, onde a música é a ferramenta essencial para possibilitar aos povos indígenas a compreensão do mundo, do seu espaço, território e reafirmação de sua identidade e cultura. Além de toda relação do povo indígena Potiguara com a cosmologia e mitologia, pois sabem a importância das fases da lua, do sol, dos tempos úteis para plantar colher e pescar.

Procurando atender à necessidade dos preceitos da diferença e especificidade na educação diferenciada indígena, tendo em vista o estabelecimento de uma valorização étnica e cultural, o MEC (Ministério da Educação e Cultura) publicou o Referencial Curricular Nacional para a Escola Indígena (RCNEI). Esse referencial está voltado prioritariamente aos professores indígenas e aos técnicos das Secretarias Estaduais de Educação, responsáveis pela implementação de programas educativos junto às comunidades indígenas.

Segundo o RCNEI (2008), os povos indígenas do Brasil, vivem em lugares e paisagens diferenciados, construindo seus espaços geográficos; seja onde for que vivam esses povos, eles se relacionam com seu espaço e criam um modo de entendê-lo e explicá-lo. É um espaço 


\section{REVISTA ELETRÔNICA \\ DA GRADUAÇÃO/PÓS-GRADUAÇÃO EM EDUCAÇÃO \\ UFG/REJ}

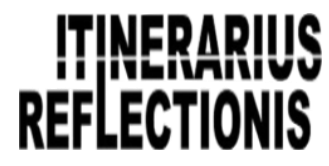

ISSN. 1807-9342

Volume 14, N. 2, 2018

sagrado, construído em profunda relação sociedade e natureza, a cultura é que define essa construção. "Cada um tem a sua maneira de entender e de se relacionar com a terra, com as águas, com as plantas, com o céu, com a chuva, com o vento, com o sol e com outros povos, outras formas de interpretação do espaço" (RCNEI, 2008, p. 225).

A geografia permite explicar o mundo por meio do estudo do espaço levando em conta o que se vê nas paisagens, (belezas naturais e destruição), com o que a pessoa se identifica nos lugares (habitação e sobrevivência) e o território (demarcação e identidade cultural).

Durante um curso de formação para professores indígenas do Acre e Sudeste do Amazonas, foram apontados pelo RCNEI, algumas falas de professores, definindo a Geografia, como:

Geografia é onde o rio está

Onde o município está.

É para onde vem o sol.

É para onde vai o sol.

Este rio para onde vai?

Geografia e a divisão das águas

É igarapé, igapó, lago, açude, mar

É a medição da terra, a demarcação

É fotografia, desenho, cor, é um mapa

É descobrir e aprender o que tem um mapa.

Geografia é o homem que transforma muitas coisas,

A mata numa cidade, a terra em roçado, a folha em remédio,

A madeira em barco, a macaxeira em farinha (BRASIL, 2008, p. 226).

Enfim, a Geografia é modo de vida da aldeia e do mundo, é a natureza, é a luta pela demarcação, é o conhecimento das paisagens e território adquirido pelos seus antepassados, permitindo assim, explicar o mundo por meio do estudo do espaço geográfico.

O estudo da Geografia alarga conhecimentos, contribui para luta contra o preconceito ainda existente, ajuda a defender e compreender seu território, economia, revitalizar sua cultura e outros. Os alunos indígenas como todos os outros, trazem para escola um conhecimento prévio, que pode ser geográfico; esse tipo de conhecimento deve ser o ponto de partida da geografia na escola, então a partir desse conhecimento, deve-se valorizar a realidade concreta vivida por cada povo indígena.

"Para o ensino da Geografia, o professor tem a tarefa de criar situações educativas que levem o aluno a comparar e analisar os diferentes conhecimentos que existem, e assim refletindo sobre o seu saber através do saber dos outros" (BRASIL, 2008, p. 245). 


\section{REVISTA ELETRÔNICA \\ DA GRADUAÇÃO/PÓS-GRADUAÇÃO EM EDUCAÇÃO \\ UFG/REJ}

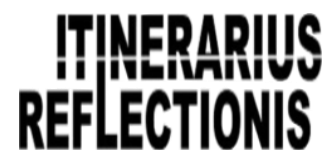

ISSN. 1807-9342

Volume 14, N. 2, 2018

Nos dias atuais, a comunicação audiovisual ocupa grande parte da vida do povo Potiguara. A música do Toré, por exemplo, é um meio envolvente que pode tornar o aprendizado em Geografia mais dinâmico, podendo assim, valorizar o conhecimento tradicional de seu grupo familiar, sua aldeia e do seu povo, sobre seu espaço e sua cultura.

O objetivo é que o aluno possa se reconhecer como também o lugar onde seu povo vive (os elementos da natureza), comparar os valores da vida social de seu povo com outros valores na sociedade, desenvolvendo atitude crítica em relação às diferenças, refletir sobre as possibilidades de melhoria ambiental em suas aldeias, valorizar a história e a ocupação espacial de seu povo inclusive os lugares sagrados, conhecer o processo territorial de sua etnia, tornando assim o ensino mais eficiente.

Através da musicalidade, é possível levantar diversos questionamentos como: Sua organização histórica, questão da territorialidade, religiosidade a preservação da natureza, as belezas naturais, mangues, matas, rios, a terra que consideram como "mãe", o desmatamento, a pesca predatória e outros.

Através da utilização da música como recurso didático, o professor será o mediador do conhecimento levando o aluno a perceber a inter-relação entre a música com o conteúdo proposto. Porém, apesar desse recurso ser importante para o desenvolvimento do trabalho escolar, especialmente para o ensino em Geografia, ele ainda é pouco aplicado.

Os recursos de apoio didático-pedagógicos em geral têm essas características por propiciarem o conhecimento intrínseco nas relações culturais de vivência do educando com o seu meio socializado, assim o educando passa a ser objeto do seu próprio saber (SILVA, 2006, p.120).

Os temas e conteúdos a serem trabalhados pelo currículo escolar precisarão estar estreitamente relacionados com a experiência de vida dos alunos. Nada melhor que a musicalidade Potiguara, e que faz parte do cotidiano: nos rituais, nas plantações, nas pescarias, nas formaturas, nas atividades domésticas e outros (RAMOS, 2010).

Segundo o RCNEI (2008), o ensino de Geografia permite ao aluno perceber o espaço geográfico, com suas paisagens e os povos indígenas possuem uma íntima relação afetiva com a natureza, seja onde for que viva uma determinada etnia, ela se relaciona com a terra, com as águas, com as plantas, com o céu, o vento, o sol, a chuva, a mata, enfim, com seu espaço geográfico. Para alguns povos indígenas o espaço geográfico é um espaço sagrado, construído 


\section{REVISTA ELETRÔNICA \\ DA GRADUAÇÃO/PÓS-GRADUAÇÃO EM EDUCAÇÃO \\ UFG/REJ}

ISSN. 1807-9342

Volume 14, N. 2, 2018

em intima relação sociedade e natureza, ou seja, o elemento definidor dessa construção é a cultura, o trabalho, a forma de apropriação do espaço.

A Geografia permite, assim, conhecer e explicar o mundo por meio do
estudo do espaço geográfico levando em conta o que se vê - as paisagens; o
que se sente e com que a pessoa se identifica - os lugares; e o que são
referências significativas para os povos e os indivíduos, para conviver e
produzir sua cultura - os territórios (BRASIL, 2008, p. 227)

Essa nova forma de ensino reconstrói uma nova história, constitui uma cidadania mais consciente, reformulando estratégias a resistência, integrando outras culturas não indígenas e novos conhecimentos para que possa melhorar as condições de vida, dentro é claro das propostas pautadas na educação escolar indígena. Além disso, reivindica uma escola que fortalece essas tradições em busca de contribuir e constituir o projeto de futuro dos indígenas.

Ainda o RCNEI afirma, "o estudo da Geografia pode alargar os conhecimentos existentes, contribui para a luta contra os preconceitos e em favor do sentimento da pluralidade e apresentar respostas sobre povos e sobre fenômenos da natureza" (BRASIL, 2008, p. 227).

A música é um recurso que ajuda a desenvolver o interesse pelos conteúdos programáticos, por ser um meio comunicativo comum, ela promove discussões que possibilitem o desenvolvimento do processo de ensino-aprendizagem.

Considerando essas questões, neste trabalho abordamos a música indígena como recurso didático para auxiliar o ensino de geografia, pois, é através do estudo e interpretação das letras entoadas (cantadas) pelos índios, que o aluno é instigado a refletir sobre a mesma, construindo conhecimento e uma consciência crítica, para valorizar sua identidade étnicocultural.

Nessa mesma linha de pensamento, Libâneo (1998), destaca que num mundo globalizado, cheio de tecnologias e diferentes linguagens, são imprescindíveis que os professores utilizem esses recursos para tornar a aula interessante e dinâmica tanto para o profissional quanto para os alunos. E sair do tradicional livro didático, do antigo método do professor copiar e os alunos re-copiar, em exercícios de monotonia e repetição.

Os professores não podem mais ignorar a televisão, o vídeo, o computador, a música, [...] que são veículos de comunicação, da aprendizagem, do lazer e informação, por que há muito tempo que o professor e o livro deixaram de ser as únicas fontes do conhecimento (LIBÂNEO, 1998, p. 40). 


\section{REVISTA ELETRÔNICA \\ DA GRADUAÇÃO/PÓS-GRADUAÇÃO EM EDUCAÇÃO \\ UFG/REJ}

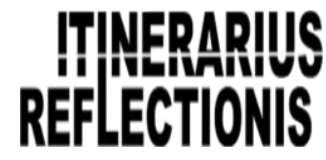

ISSN. 1807-9342

Volume 14, N. 2, 2018

Utilizar novas metodologias de ensino que consigam inserir os alunos no seu contexto social, através de diálogos e debates, irá tornar o ensino de Geografia algo produtivo e ligado com os pensamentos e inovações do mundo moderno, o qual nossos alunos estão inseridos. É importante para o índio porque irá fortalecer sua identidade cultural, do seu povo e outros modos de viver, desenvolver uma autoestima em relação aos modos de vida de sua aldeia. A busca por novas metodologias deve fazer parte do cotidiano dos professores, na qual inserimos a música indígena.

Dentre essa proposta o aluno vai estar envolvido em uma experiência educativa em que o processo de construção do conhecimento está integrado às práticas vividas no seu cotidiano. A geografia permite ao aluno perceber o espaço geográfico, com suas paisagens e os povos indígenas possuem uma íntima relação afetiva com a natureza. Para eles tudo o que os cerca é o espaço geográfico. Pensando essa relação, faz-se necessário indicar algumas possibilidades para tratamento da música nessa realidade escolar, a partir do ensino de geografia.

\section{ALGUMAS SUGESTÕES DE MÚSICAS INDÍGENAS APLICADAS AO ENSINO DE GEOGRAFIA}

Neste momento, iremos tratar da discussão de algumas músicas indígenas que podemos utilizar como metodologia de ensino nas aulas de geografia, pois, essas músicas abordadas, tratam de importantes conteúdos geográficos, facilitando assim o aprendizado da geografia e dinamizando as aulas, para que não fique tão fora do contexto da educação diferenciada indígena.

\section{Música 1}

Nossas matas eram verdes

Purificava nosso ar

Hoje estão todas as queimadas

Não podemos respirar

Nossos mangues e marés

Tinham peixe e camarão

Caranguejo, ostra e marisco

Está tudo em extinção

Para Tudo isto mudar, Precisamos nos unir,
Nós unimos venceremos

E não vamos desistir.

(Dona Conceição, aldeia Tramataia)

\section{Música 2: Destruição}

Quando olhei as nossas matas

Numa triste destruição

Os animais estão morrendo

Graças o homem sem coração

Que beleza eram essas matas

Dá vontade de chorar 


\section{REVISTA ELETRÔNICA \\ DA GRADUAÇÃO/PÓS-GRADUAÇÃ̃ EM EDUCAÇÃO UFG/REJ}

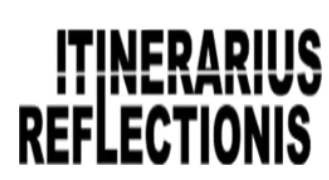

ISSN. 1807-9342

Volume 14, N. 2, 2018
Ouvindo o canto dos passarinhos

Fugindo solto em seu caminho

Até mesmo os nossos rios

Estão sendo destruídos

Cortando as árvores de suas margens

Mudando o curso já poluído

Hoje vejo muitas árvores

Cortadas e até queimadas

Eu fico triste nesse instante

Por que tamanha destruição
Quando o verde dessas matas

Tocar no teu coração

Vendo tudo o que fizeste

Com o teu povo e o teu irmão
A natureza é nossa Mãe

Jamais perdoa um filho seu

Que tenta ela destruir

Com arrogância e ambição.

(Francinaldo Gûyraguasu - Potiguara da Aldeia Akajutibiró/PB)

Nessas músicas podemos abordar a questão ambiental, porém é importante lembrar que existem várias concepções/conceitos acerca do que é meio ambiente. De acordo com Branco (1997, p. 8), meio ambiente é o “conjunto de elementos e fatores físicos, químicos e biológicos, necessários à sobrevivência de cada espécie", ou seja, é o conjunto de fatores que cercam as espécies e tornam possível sua vida.

A falta de conhecimento sobre a dinâmica ambiental contribui para seu processo de degradação. Pensando essa questão, devemos, a partir da discussão dessa temática, conscientizá-los para a preservação, já que essa dimensão é tão importante para a sobrevivência desse povo, pois, não só é o branco que desmata como também, o índio faz parte desse quadro de desmatamento. O que será do povo Potiguara sem a presença de um ambiente preservado?

O desmatamento e a poluição que vem ocorrendo nas matas, rios e mangues nas áreas territoriais dessas aldeias Potiguara, em especial na aldeia Monte-Mor e na aldeia Tramataia, é muito preocupante, pois, eles desmatam para extrair as madeiras para construir casas de taipas, carvoeiras (onde é feito o carvão), e até mesmos vender para outras pessoas. Nos mangues principalmente nas aldeias de Tramataia e Camurupim ambas localizadas no município de Marcação, a mata é destruída para construção de viveiros de camarão (carcinocultura), bem como a pesca predatória que é um grande problema enfrentado.

Ainda Branco (1997, p. 20) afirma que, “impacto ambiental é, pois, uma espécie de trauma ecológico que segue ao choque causado por uma ação ou uma obra humana em desarmonia com as características e o equilíbrio do meio ambiente". 


\section{REVISTA ELETRÔNICA \\ DA GRADUAÇÃO/PÓS-GRADUAÇÃ̃O EM EDUCAÇÃO \\ UFG/REJ}

ISSN. 1807-9342

Volume 14, N. 2, 2018

De maneira geral, o meio ambiente está muito afetado pela ação do ser humano. São inúmeros os fatores que contribuíram para o agravamento do atual estágio de devastação da vegetação natural Potiguara, dentre os quais, a monocultura canavieira, que tem provocado o desaparecimento das restingas, das matas, dos rios e dos tabuleiros costeiros, o empobrecimento do solo, bem como a gradativa extinção de toda a biodiversidade (SILVA, 2015).

\section{Música 3: Sou Potiguara}

Sou Tupã, sou Tupã, sou Potiguara.

Sou Potiguara nesta terra de Tupã,

Tenho arara, craúna e xexéu.

Todos os pássaros do céu,

Quem me deu foi Tupã,

Foi Tupã, sou Tupã, sou Potiguara.

Na música 3, podemos fazer uma reflexão da identidade étnica deste povo, demonstrar o orgulho que possuem de ser da etnia Potiguara, como também a valorização da religiosidade, ao seu Deus Tupã, que está sendo perdida por muitos da etnia. Isso está relacionada ao fato de que durante muitos anos foi respeitada por todos indígenas antepassados e hoje, vemos que a cada dia está sendo desconsiderada a religiosidade ligada ao Deus Tupã.

Ainda nesta música podemos falar da nossa fauna e flora, das diversidades que ainda se encontra nas nossas matas como os tipos de pássaros, animais, as árvores, as plantas e outros.

\section{Música 4:}

A terra é santa

A terra é mãe

A terra é do índio

A terra é de Deus

O povo que luta

Com força e união

Pra gente é sinal

De libertação
Vamos plantar mandioca

Pra nos alimentar (Pedro Máximo - aldeia

Monte-Mór)

Aqui plantamos e tudo dar O índio quer terra pra cultivar

Da manga, caju e maracujá

A cultura do meu povo

Já não pode acabar 


\section{REVISTA ELETRÔNICA \\ DA GRADUAÇÃO/PÓS-GRADUAÇÃO EM EDUCAÇÃO \\ UFG/REJ}

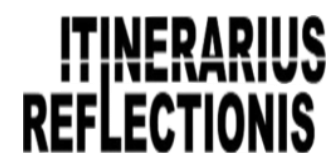

ISSN. 1807-9342

Volume 14, N. 2, 2018

Na letra desta música podemos analisar a dinâmica da questão territorial como forma de sobrevivência, (moradia e plantação), lutas pela oficialização da demarcação, localização e outras.

Ensinar Geografia a partir da música indígena, é uma tarefa que requer muita pesquisa e atenção, pois, no primeiro momento irá se fazer uma pesquisa e análise, musicográfica, depois, analisar qual o conteúdo geográfico, podemos abordar na música escolhida, e que esteja de acordo com sua realidade, e no terceiro momento levar para sala de aula, escutar, cantar, refletir, debater e ensinar.

Essas cantorias podem ser escutadas e lidas em forma de rituais em círculo, na sala de aula, assim eles irão entender aos poucos, nos momentos reflexivos, o quanto as músicas repassam momentos vividos por eles, reforça sua etnia, demonstram sua cultura, numa visão que eles possam perceber a importância destas.

Assim podemos afirmar que essas discussões ao utilizar as melodias servem tanto para o aprendizado geográfico, quanto para o processo de valorização da identidade étnica e cultural do povo Potiguara.

\section{CONSIDERAÇÕES FINAIS}

Diante do desafio e das dificuldades em transformar o ensino de Geografia, implantado na educação escolar indígena, em um instrumento capaz de despertar uma reflexão sobre a realidade dos povos indígenas Potiguara e a valorização étnica e cultural, o professor indígena frequentemente tem encontrado grandes dificuldades para despertar a atenção de seus alunos, especialmente porque estes consideram a maioria dos conteúdos aplicados em sala de aula, monótonos e enfadonhos.

Assim, para superar esses problemas de ensino, relacionados as aulas de Geografia, é necessário buscar novas metodologias e recursos inovadores para tornar as aulas mais dinâmicas, interessantes, que estimulem o desenvolvimento do raciocínio, da criatividade e do pensamento crítico dos alunos.

Para isto, a música indígena Potiguara, surge neste contexto como forma de revitalização étnica e cultural e uma inovação para o professor, motivando o aluno a adquirir novos conhecimentos de forma prazerosa nos conteúdos geográficos, para ter uma maior compreensão do espaço geográfico vivido e observado por eles. 


\section{REVISTA ELETRÔNICA \\ DA GRADUAÇÃO/PÓS-GRADUAÇÃO EM EDUCAÇÃO \\ UFG/REJ}

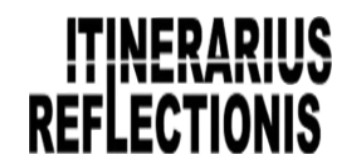

ISSN. 1807-9342

Volume 14, N. 2, 2018

As melodias Potiguara possibilitam ao aluno o desenvolvimento de diversas habilidades, tais como observar e analisar espaço geográfico, estabelece momentos vividos por eles, conscientizam, sensibilizam, valorizam sua identidade e cultura local, além de possibilitar ao alunado aproximar o conteúdo e o conhecimento desenvolvido na escola, com o espaço que o mesmo está habituado, que é sua realidade.

O uso da música indígena Potiguara contribui para que o ensino de geografia cumpra seu papel enquanto instrumento de fortalecimento étnico e cultural, na medida em que permite discutir temas do cotidiano, facilitando assim o aprendizado dos conteúdos geográficos.

\section{AGRADECIMENTOS}

Agradeço ao do Grupo de Pesquisa Ensino, Aprendizagem e Formação de Professores em Geografia da Universidade de Brasília (GEAF-UnB) pelos momentos de reflexões durante a enlevada deste trabalho.

\section{REFERÊNCIAS}

BARCELLOS, Lusival. Práticas educativo-religiosas dos índios Potiguara da Paraíba. João Pessoa: Editora da UFPB, 2012.

BRANCO, Samuel Murgel. O Meio Ambiente em Debate. Coleção Polêmica. $26^{a}$ Ed. São Paulo: Moderna, 1997, 96p.

BRASIL. Referencial Curricular Nacional para Escolas Indígenas (RCNEI) / Ministério da Educação e do Desporto, Secretaria de educação fundamental. Brasília: $2008 \mathrm{MEC} / \mathrm{SEF}$.

CARDOSO, Thiago Mota; GUIMARÃES, Gabriella Casimiro. (Orgs.).

Etnomapeamento dos Potiguara da Paraíba. Brasília:

FUNAI/CGMT/CGETNO/CGGAM, 2012. (Série Experiências Indigenas, n. 2)

ELIADE, Mircea. Mitos e realidade. São Paulo: Perspectiva, 2007.

LEITE, Cristina Maria Costa. O lugar e a construção da identidade: os significados construídos por professores de Geografia do ensino fundamental. Tese (doutorado) Universidade de Brasília -Faculdade de Educação - Programa de Pós Graduação em Educação, 2012. 


\section{REVISTA ELETRÔNICA \\ DA GRADUAÇÃO/PÓS-GRADUAÇÃO EM EDUCAÇÃO UFG/REJ}

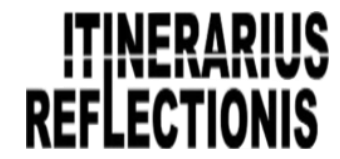

ISSN. 1807-9342

Volume 14, N. 2, 2018

LIBÂNEO, José Carlos. Didática. 28. ed. São Paulo: Cortez, 1998. (Coleção magistério. Série formação do professor).

MARQUES, Amanda Christinne Nascimento.Território de Memória e

Territorialidades da Vitória dos Potiguara da aldeia Três Rios/ Amanda Marques JoãoPessoa, 2009. 217f. : il.Orientadora: Maria de Fátima Ferreira Rodrigues Dissertação (Mestrado) - UFPB/ CCEN/ PPGG.

MARQUES, Cássio Ferreira. (Org.). Lendas e Causos do Povo Potiguara. João Pessoa: Editora da UFPB, 2009.

Os Potiguaras pelos Potiguaras. Professores e Alunos Potiguara. - João Pessoa: AER de João Pessoa; Brasília: CGDOC/FUNAI, 2005.

PALITOT, Estevão Martins. Os Potiguara da Baía da Traição e Monte-Mór: história, etnicidade e cultura. 2005. Dissertação (Mestrado em Sociologia) Universidade Federal da Paraíba, 2005.

RAFFESTIN, Claude. Uma concepção de território, territorialidade e paisagem. In: PEREIRA, S. R.; COSTA, B. P.; SOUZA, E. B. C. (Orgs.). Teorias e práticas territoriais: análises espaço-temporais. São Paulo: Expressão Popular, 2010.

RAMOS, Leandro da Siva. "Sou Tupã, sou Potiguara": as músicas indígenas como metodologia de ensino. 2010. Monografia. Universidade Estadual da Paraíba. Guarabira, 2010.

SAQUET, Marcos. Por uma Geografia das territorialidades e das temporalidades: uma concepção multidimensional voltada para a cooperação e para o desenvolvimento territorial. São Paulo: Outras Expressões, 2011.

SILVA, Antonio de Pádua Dias da. Ensino de língua: do impresso ao virtual. Campina Grande: EDUEP, 2006.

SILVA, Sidnei Felipe da. Educação Ambiental em Terras Indígenas Potiguara: concepções e possibilidades na educação de jovens e adultos nas escolas estaduais indígenas do município de Rio Tinto-PB. Saarbrücken, Deutshland:OmniScripitium GmbH \& CO. KG, 2015.

SOLER, Juan. BARCELLOS, Lusival Antonio. Paraíba Potiguara. João Pessoa: Editora Universitária UFPB, 2012.

VIEIRA, J. G. A Baía da Traição, das belezas "naturais" e do refúgio dos "índios resistentes". In: ALMEIDA, L. S.; Silva, C. B. M. (Org.) Índios do Nordeste: temas e problemas 4. Maceió: EDUFAL, 2004. 